\title{
Florence Paravy (dir.), Littératures africaines et comparatisme
}

\section{Emanuela Cacchioli}

\section{Q OpenEdition \\ 1 Journals}

\section{Edizione digitale}

URL: http://journals.openedition.org/studifrancesi/3890

DOI: 10.4000/studifrancesi.3890

ISSN: 2421-5856

\section{Editore}

Rosenberg \& Sellier

\section{Edizione cartacea}

Data di pubblicazione: 1 décembre 2012

Paginazione: 618-619

ISSN: 0039-2944

\section{Notizia bibliografica digitale}

Emanuela Cacchioli, «Florence Paravy (dir.), Littératures africaines et comparatisme», Studi Francesi [Online], 168 (LVI | III) | 2012, online dal 30 novembre 2015, consultato il 07 mars 2021. URL: http:// journals.openedition.org/studifrancesi/3890 ; DOI: https://doi.org/10.4000/studifrancesi.3890

Questo documento è stato generato automaticamente il 7 mars 2021.

\section{(c) (i) (9)}

Studi Francesi è distribuita con Licenza Creative Commons Attribuzione - Non commerciale - Non opere derivate 4.0 Internazionale. 


\title{
Florence Paravy (dir.), Littératures africaines et comparatisme
}

\author{
Emanuela Cacchioli
}

\section{NOTIZIA}

FLORENCE PARAVY (dir.), Littératures africaines et comparatisme, préface de Jean-Marc MOURA, Metz, Centre Écritures/APELA, 2011, pp. 214.

1 La raccolta di saggi curata da Florence PARAVY e pubblicata con il sostegno dell'Association pour l'Étude des Littératures africaines (APELA) è il risultato degli atti del convegno che si è tenuto il 26 e 27 settembre 2008 presso l'Université de Paris Ouest Nanterre La Défense. Nella prefazione Jean-Marc MOURA sottolinea che in Francia si nota una certa resistenza ad inserire le letterature extra-europee all'interno degli studi comparatistici. Questo volume manifesta, al contrario, la vivacità intellettuale e l'attenzione critica verso le letterature africane e i possibili approcci che ci consentono di studiarle in ottica comparatistica. Possiamo individuare tre orientamenti che si articolano in prospettive complementari nei vari interventi: uno studio interculturale che fa leva essenzialmente sulle letterature orali; una possibile lettura sociopolitica e geocritica delle opere; un'interpretazione filologica che si basa su questioni plurilinguistiche.

2 I saggi sono suddivisi in quattro sezioni che comprendono ciascuna tre interventi. Nella prima parte, intitolata "Quelles frontières pour les études littéraires?», Charles BONN, Comparatisme français et littératures francophones de pays anciennement colonisés: quelle ouverture? (pp.13-21), illustra come gli studi di comparatistica possano favorire un métissage culturale e si caratterizzino come punto di partenza privilegiato per condurre un'analisi critica sulla letteratura mondiale. Lo studio di Molly GROGAN LYNCH, Quelle place pour l'Afrique dans la World Literature? (pp. 23-47), indaga la World Literature, intesa come processo di lettura di un testo in una cultura altra rispetto a quella che l'ha prodotto, e lo spazio che una letteratura essenzialmente orale come quella africana 
trova all'interno delle antologie. Segue il saggio di Dominique RANAIvoson, Quelles couleurs pour l'Afrique littéraire? (pp. 49-62), in cui si profila un'indagine comparatistica intra-africana che fa appello ad una rinegoziazione dell'identità di un continente che non può essere considerato come blocco monolitico. La seconda sezione, «Horizons continentaux», inizia con l'intervento di Ursula BAUMGARDT, Littératures africanes orales et écrites: quelle comparaison? (pp. 65-81), che ci suggerisce di affrontare i testi orali africani a partire da un'analisi del contesto di produzione e di "consumo" delle opere letterarie. In Les trois littératures swahilies (pp.83-95), Elena BERTONCINI rintraccia le origini, gli aspetti comuni e divergenti che caratterizzano le letterature in lingua swahili a Zanzibar, nella Tanzania continentale e in Kenia. Christine LE QUELLEC COTTIER, Roman d'apprentissage et liberté romanesque (pp.97-108), si focalizza sulle dimensioni sincroniche e diacroniche che permettono al romanzo di formazione di essere metafora di un'autonomia linguistica e letteraria acquisita progressivamente. Apre la terza sezione, «Littératures africaines et héritage européen», Bernard MOURALIS con Littératures africaines et antiquité gréco-romaine (pp.111-125) in cui si pone in evidenza l'uso estetico e retorico dei riferimenti classici attinti dalla letteratura africana, oltre alla riflessione storica e filosofica che si dipana a partire dalla nozione di colonialismo. Benoît CONORT, Le lamantin, de quelle rive crie-t-il? Léopold Sédar Senghor et l'élégie grécoromaine (pp.127-135), si concentra, invece, sulla poesia e ci spiega come Léopold Sédar Senghor si inserisca nella tradizione elegiaca pur sovvertendone i riferimenti per esprimere meglio lo spirito del poeta africano. Anche il saggio di Marie LEFÈVRE è un esempio tangibile di come possa essere sviluppato uno studio comparato tra scrittori africani ed europei, così come si evince dal titolo: Le "fusil à deux coups» d'Ahmadou Kourouma. Lecture comparée de "Allah n'est pas obligé» et "Quand on refuse, on dit non», à la lumière de "Candide» de Voltaire et "Jacques le fataliste» de Diderot (pp. 137-151). La quarta sezione, «Migrations et diaspora», ci presenta tre saggi in cui si rintracciano alcuni esempi di raffronti tra autori africani rimasti in patria e altri emigrati in Europa, oppure si prefigura uno studio che prende in considerazione tre scrittori africani di aree differenti. Ieme VAN DER POEL, con Le drame des harragas vu de près et de loin: Youssef Amine Elalamy rencontre Hafid Bouazza (pp. 155-169) mette in relazione due testi scritti da autori marocchini di espressione nederlandese e francese. Le intenzioni di Germain NYADA sono evidenti già dal titolo: Enfance et poétique interculturelle: un récit kurde germanophone et un récit camerounais francophone (pp.171-183). Chiude il volume l'intervento di Manfred LOIMEIER, L'équateur littéraire. Les relations tri-continentales dans les cuvres de Tierno Monembo (Guinée), Abdulrazak Gurnah (Tanzanie) et José Eduardo Agualusa (Angola) (pp. 185-194). 